\title{
GEODYNAMIC ZONING FOR UNDERGROUND ISOLATION OF RADIOCTIVE WASTE
}

\author{
Vladislav Morozov, Alexander Kagan \\ Geophysical Center of Russian Academy of Sciences \\ 117296, Moscow, Molodezhnaya 3 \\ Ph.: +7(495)930-5639, fax: +7 (495)930-0506; e-mail: aleck.kagan@ gmail.com
}

\begin{abstract}
The problem of area selection for underground isolation of radioactive waste is important for all countries using nuclear power. The paper presents the results of modeling the stress-deformed state of Nizhnekanskiy granitoid massif and shows the possibility of using such simulations for the geodynamic zoning of areas. The calculation is given to the most probable directions of groundwater filtration, which is one of the main threats for the nuclear waste repository.
\end{abstract}

Keywords: high-level radioactive wastes, stress-deformed state, filtration of groundwater, Niznekansky granitoid massif.

\section{Introduction}

The development of nuclear power in Russia is impossible without resolution of the problem of high-level radioactive waste (HLRW) disposal in deep geological formation. The selection of sites for the environmentally safe underground isolation of high-level radioactive solidified waste remains to be the major problem for the states that use nuclear energy, such as Russia. Methodologically, the choice of the site for HLRW disposal is based on the finding in the relatively stable areas of the least disturbed structurally tectonic blocks (STB), which have maximum size [1] [2].

The expert assessments of the current "quality" of the site where the HLRW repository will be built, do not answer the fundamental question: how will the tectonics affect the rock mass safety during 100 thousand years and more, until there will be an environmental hazard of radionuclide.

The greatest threat is the formation of new faults or intensification of the existing tectonic faults and infiltration of surface water and groundwater to containers with high-level radioactive waste (HLRW), followed by the removal of the radionuclide in the human environment.

The basic principle of ensuring safe disposal of nuclear waste is to prevent the formation of zones of dangerous stress concentrations at the design phase of nuclear fuel (SNF) repository on the basis of geodynamic zoning. The forecast of the evolution of the stress-deformed state (SDS) of the geological environment from a position of insulating properties of rock masses as a major barrier against the spread of radionuclide is required.

The purpose of this paper is to analyze the possible development of the tectonic process in Niznekansky granitoid massif on the basis of structural-tectonic model and calculation of the stress-deformed state of the local area. The most probable direction of groundwater filtration under the influence of tectonic stress is simulated.

\section{Materials and methods}

Niznekansky granitoid massif (NKM) is located a few kilometers to the north-east of Krasnoyarsk. Three sites for HLRW disposal: "Kamenniy", "Itatskiy" and "Eniseiskiy" were selected according to the geological and geophysical, structural, and geomorphologic studies in the western part of the massif, and partly in the surrounding rocks [3]. 
The analysis of geological data displays [3] that the stress-deformed state (SDS) of the massif is determined mainly by compressive forces oriented towards the south-west - north-eastern direction.

We used an elastic model of generalized plane stress for simulate the stress-deformed state. We used finite element method (FEM) as a method of calculation. Empowering the finite element with different mechanical properties enables to generate a heterogeneous finite element model, which reflects the real properties of rock massif. Fig. 1 displays a structural model of NKM to simulate the distribution of stress fields by FEM. We took the following values of the tectonic stress: sub latitudinal $\mathrm{N}_{\mathrm{x}}=30 \mathrm{MPa}$ and sub meridian $\mathrm{N}_{\mathrm{y}}=10 \mathrm{MPa}$. These values are close to the stresses in the undisturbed rocks measured in the underground workings [4] at depths of up to $400 \mathrm{~m}$. Detailed program of the stress calculation is presented in [5].

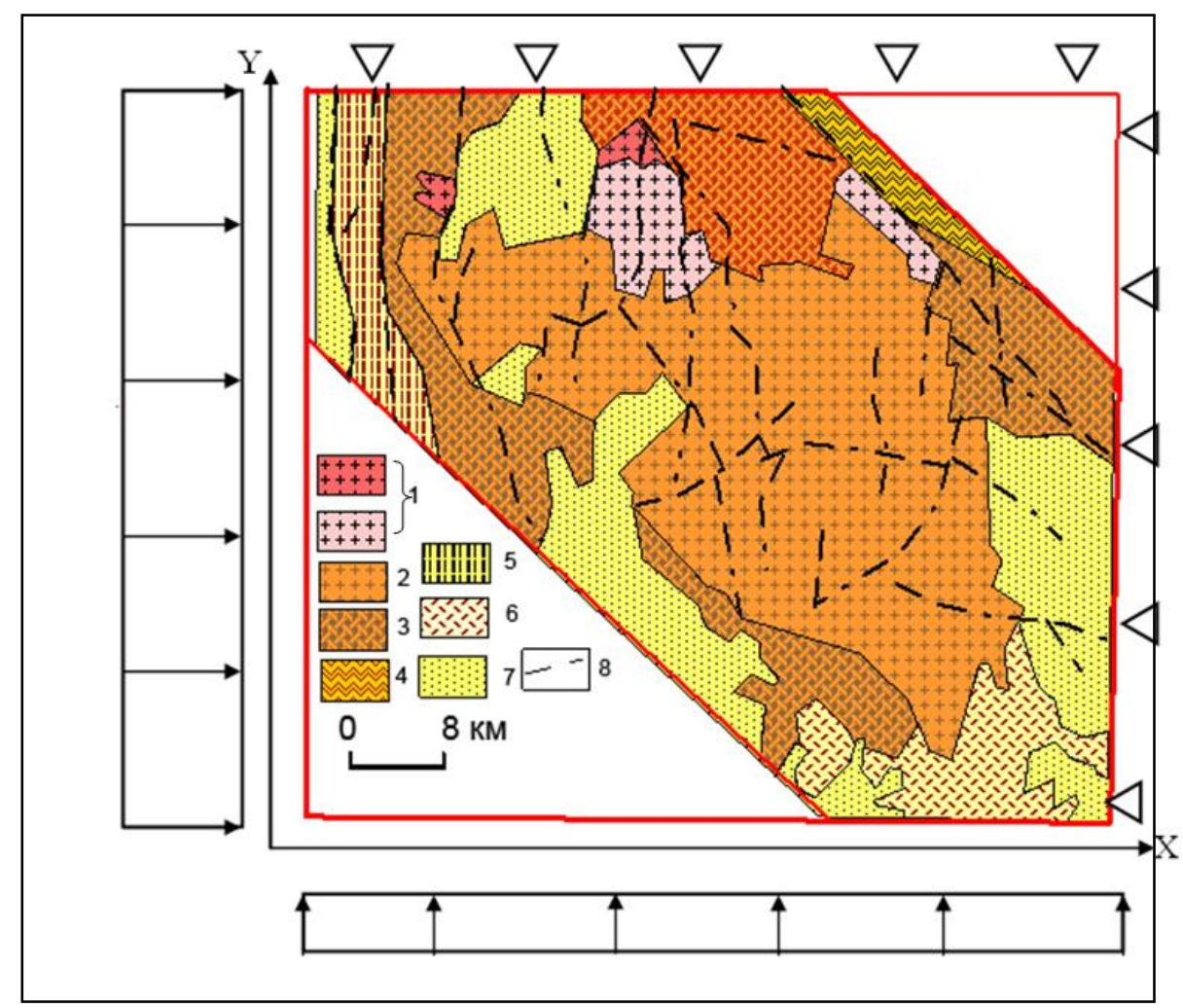

Fig. 1. Structural model for simulate the distribution of stress fields by FEM

1, 2- contour of NKM granitiods differ in their elastic-strength properties, 3- gneiss complex (AR); 4mylonite areas, 5- amphibolite, quartzite and marble (AR-PR); 6- terrigenous-volcanic deposits $\left(\mathrm{PZ}_{2}\right)$; 7- terrigenous deposits $(\mathrm{J}) ; 8$ - main faults

\section{Results and discussion}

We used stress intensity $\sigma_{i}$ as a generalized criterion of the level of SDS of the local areas NKM. Figure 2 displays contour map distribution of stress in the NKM. Figure 3 displays 3-D model of the distribution of stress intensity. 


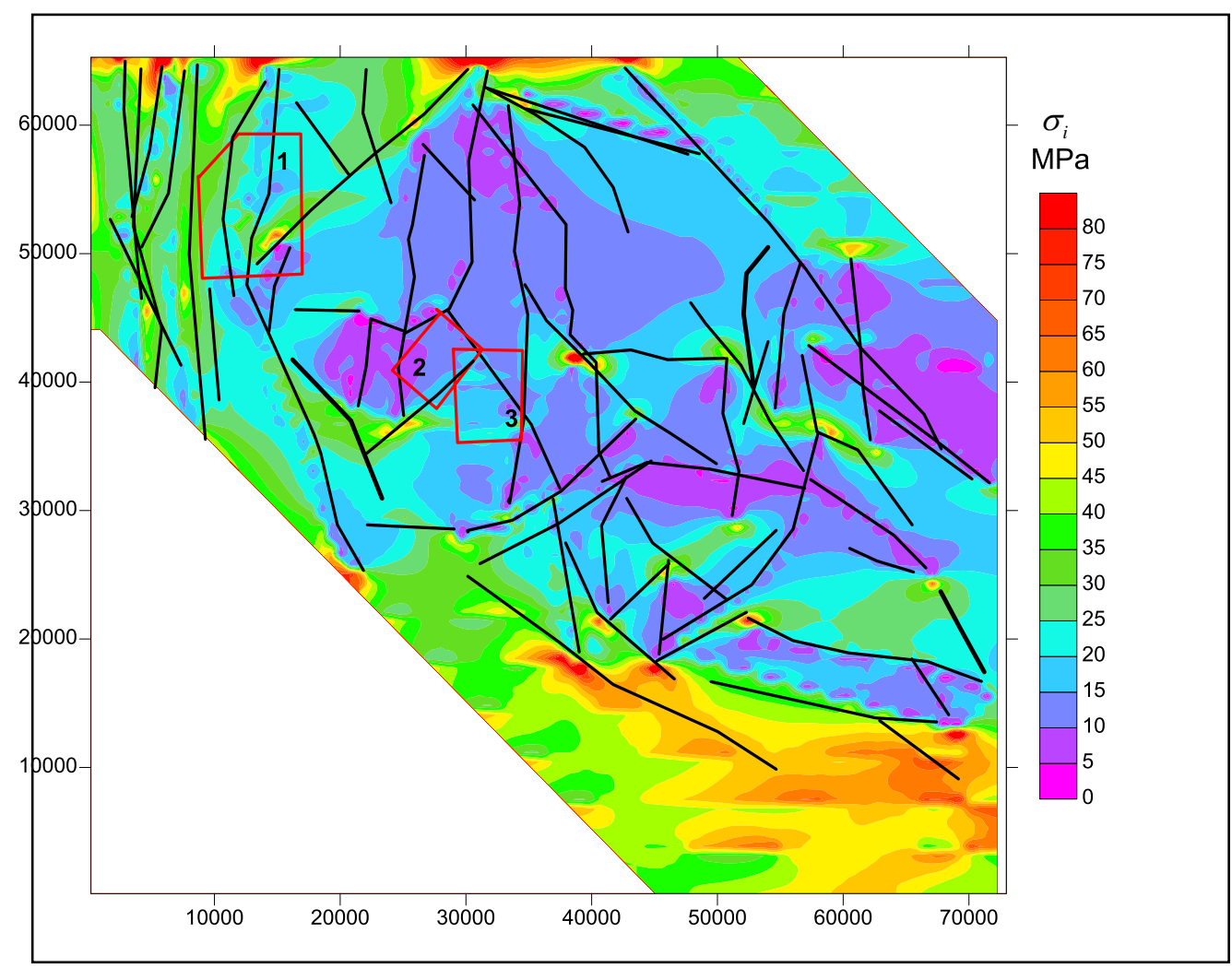

Fig. 2. Distribution of stress intensity in the NKM according to calculations by finite element method. Lines indicate faults

The rectangles marked areas of detailed studies: 1- "Eniseiskiy", 2- Itatskiy, 3- "Kamenniy"

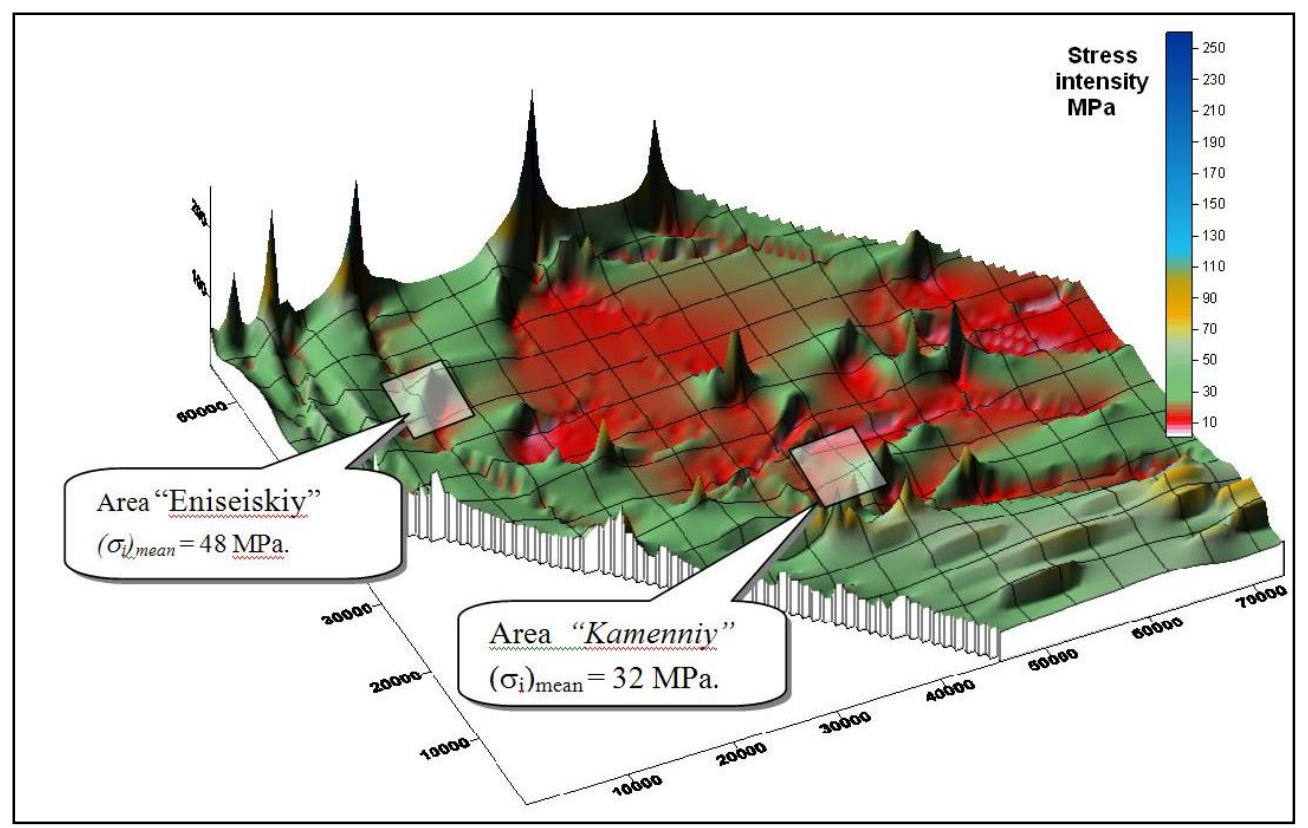

Fig. 3. 3D model of the distribution of stress intensity in the NKM

The high level of differentiation distribution of the stress intensity $\sigma_{i}$ within the model of NKM gives rise to the selection of potentially dangerous areas (not suitable for isolation of HLRW). 3-D model is the basis for virtually geodynamic zoning in the purpose to select the areas geoenvironmentally safe for underground isolation of HLRW in geological formation. 
We can confidently assert that the zones of stresses intensity concentration are possible sources of large-scale destruction of the geological environment in the working tectonic stress fields.

One of the major threats for the reliability of HLRW repository is the penetration of ground water to the containers, followed by removal of radionuclide in the human environment.

Filtration through an environment is described by Darcy's law:

$$
V_{x}=-\frac{k}{\mu} \frac{d P}{d x}
$$

where $V$ - value of the filtration rate through a porous environment; $k$ - permeability of the medium; $\mu$-dynamic viscosity of fluid; $P$ - pressure.

Coefficient $k$ is constant for a given liquid, if the porous environment is incompressible and isotropic.

For an isotropic environment the equation can be written:

$$
V=-\frac{k_{0}}{\mu} \nabla(P)
$$

where $V$ - velocity vector of the filtration. Applying the divergence operation we receive:

$$
-\frac{k_{0}}{\mu} \nabla^{2}(P)=0
$$

Thus, filtration through the isotropic environment can be reduced to solving the Laplace equation with appropriate boundary conditions. If the distribution $P$ is known, then the filtration rate can be obtained from Darcy's law in the form (2).

In many cases, the porous environment is anisotropic and the permeability depends on the direction of flow. In this case, the equation can be written as:

$$
\frac{\partial^{2} P}{\partial x^{2}}+\frac{\partial^{2} P}{\partial y^{2}}+\frac{\partial^{2} P}{\partial z^{2}}=0
$$

Thus, we have the Laplace equation again. Consequently, the true physical meaning can be represented as a fictitious isotropic in the transformed coordinates.

In accordance with Darcy's law, we proceed from the assumption that the filtration rate in the gradient field of the tectonic stress is proportional to the gradient of the effective stress:

$$
\overrightarrow{V_{f}}=\left[\begin{array}{l}
\overrightarrow{V_{x}} \\
\overrightarrow{V_{y}}
\end{array}\right]=\left[\begin{array}{l}
k E \nabla^{2} U \\
k E \nabla^{2} V
\end{array}\right]
$$

Assuming that filtration coefficient is a constant.

The filtration rate is expressed in terms of stress components, in a plane-stressed state:

$$
\overrightarrow{V_{f}}=\overrightarrow{V_{x}}+\overrightarrow{V_{y}}=k E\left(\sigma_{x x}+\sigma_{y y}\right)
$$

Using these equations, it is possible to calculate and predict the development of hydrogeological conditions in the area of hypothetical construction of nuclear waste repository at the change of SDS rock mass as a result of the predicted tectonic destruction of the rock mass.

Note, that the filtration velocity vector is orthogonal to the direction of the effective forces that cause compression along the respective axes in this coordinate system.

The level of the stress state of the rock massif in its local zones is defined by the value of stress intensity. Transfer to the stress intensity allows you to build a model of liquid filtration independent from that particular system of coordinates. Based on the assumption that the filtration rate is determined by this integral assessment of the level of working stress in the volume element of rock mass, we get:

$$
\overrightarrow{V_{f}}=\operatorname{grad}\left(\sigma_{i}\right)
$$


This simplifies the calculations of the first approximation, since the problem of estimating the stress state and filtration are solved separately. In this case, the filtration rate makes it possible to count water inflows in the weakened zones of tectonic fractures as a basis for further calculations of the migration rate and the predicted migration of radionuclide in the mass transfer process.

Figure 4 displays the calculation of the gradients vectors $\vec{G}=\left\langle\operatorname{grad} \frac{\sigma_{i}}{2}\right\rangle$ of the working tectonic stress for NKM.

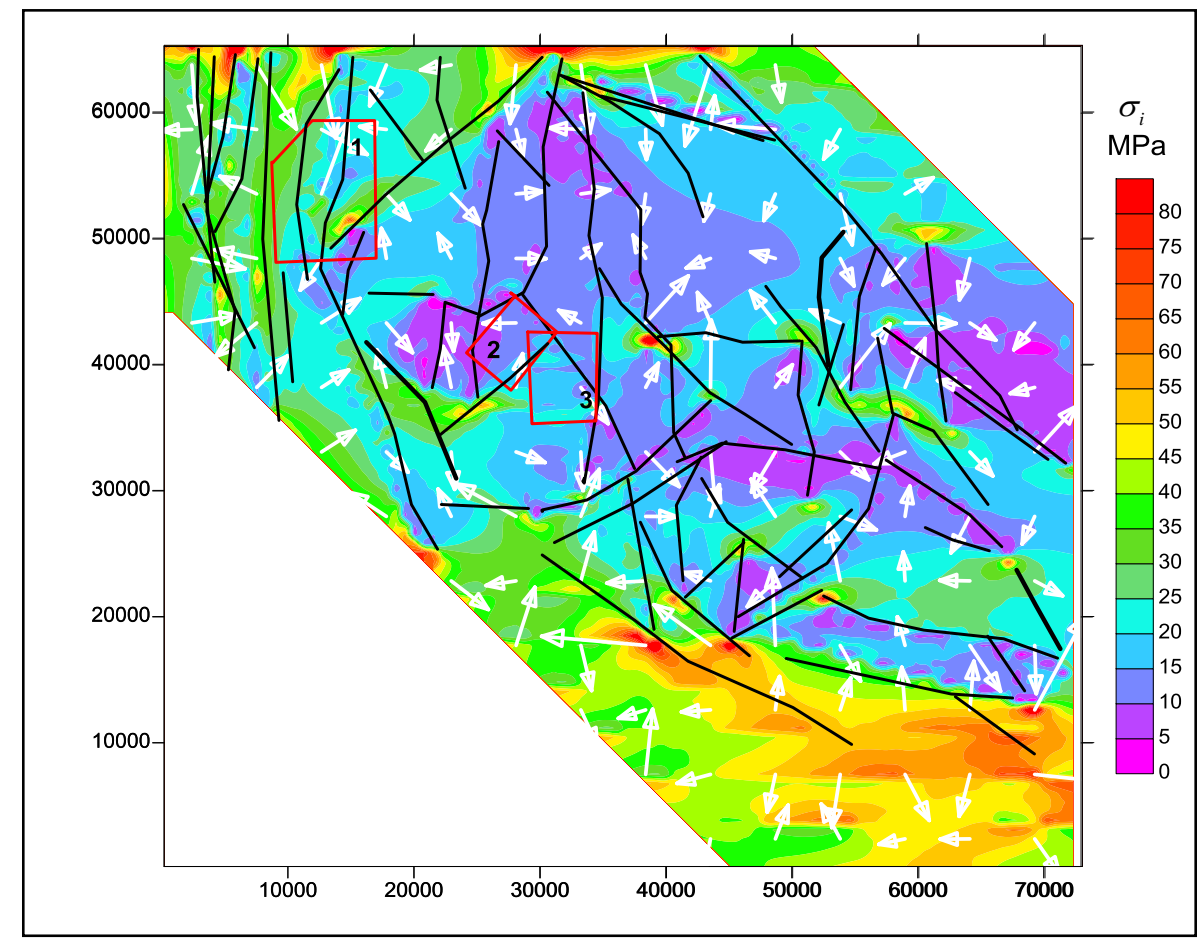

Fig. 4. Vectors of filtration rate in NKM

At the present time, area «Eniseiskiy» is the most promising in terms of creating a repository for HLRW. On this basis, we simulated the stress-deformed state of rock massif within the area «Eniseiskiy». The boundary conditions for this simulation were taken from the model for NKM.

Figure 5 displays the calculated vectors of filtration rate for «Eniseiskiy» area. Vector indicates the most probable direction of groundwater filtration under the influence of tectonic stress. 


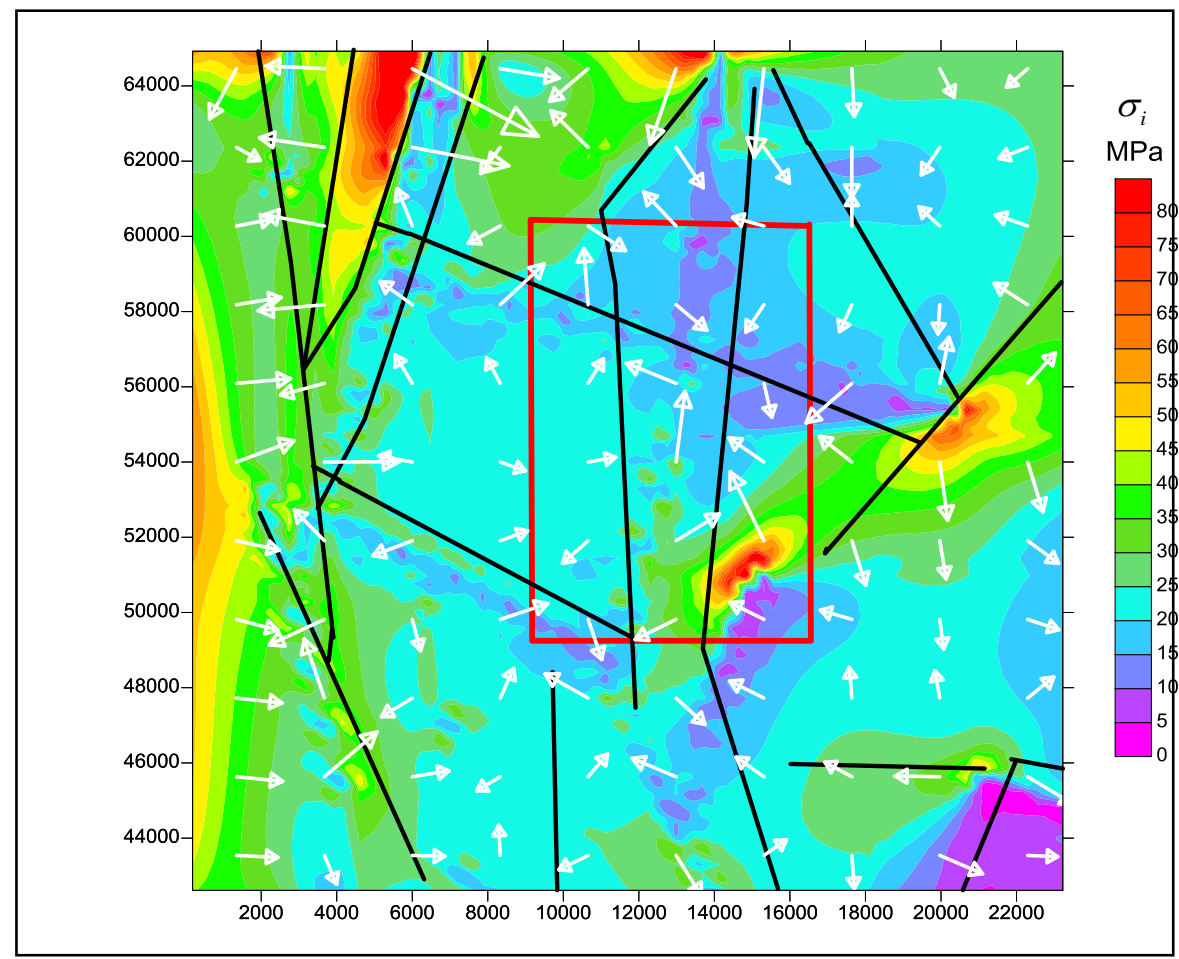

Fig. 5. Vectors of filtration rate in area «Eniseiskiy»

Fig. 6 displays the concentration of shear stresses for area «Eniseiskiy». The areas with maximum level of shear stress concentration are potentially dangerous from the position of the formation of tectonic movements, i.e. formation of tectonic faults containing the shear component. The risk of faults is more likely in areas of high concentration of shear stress.

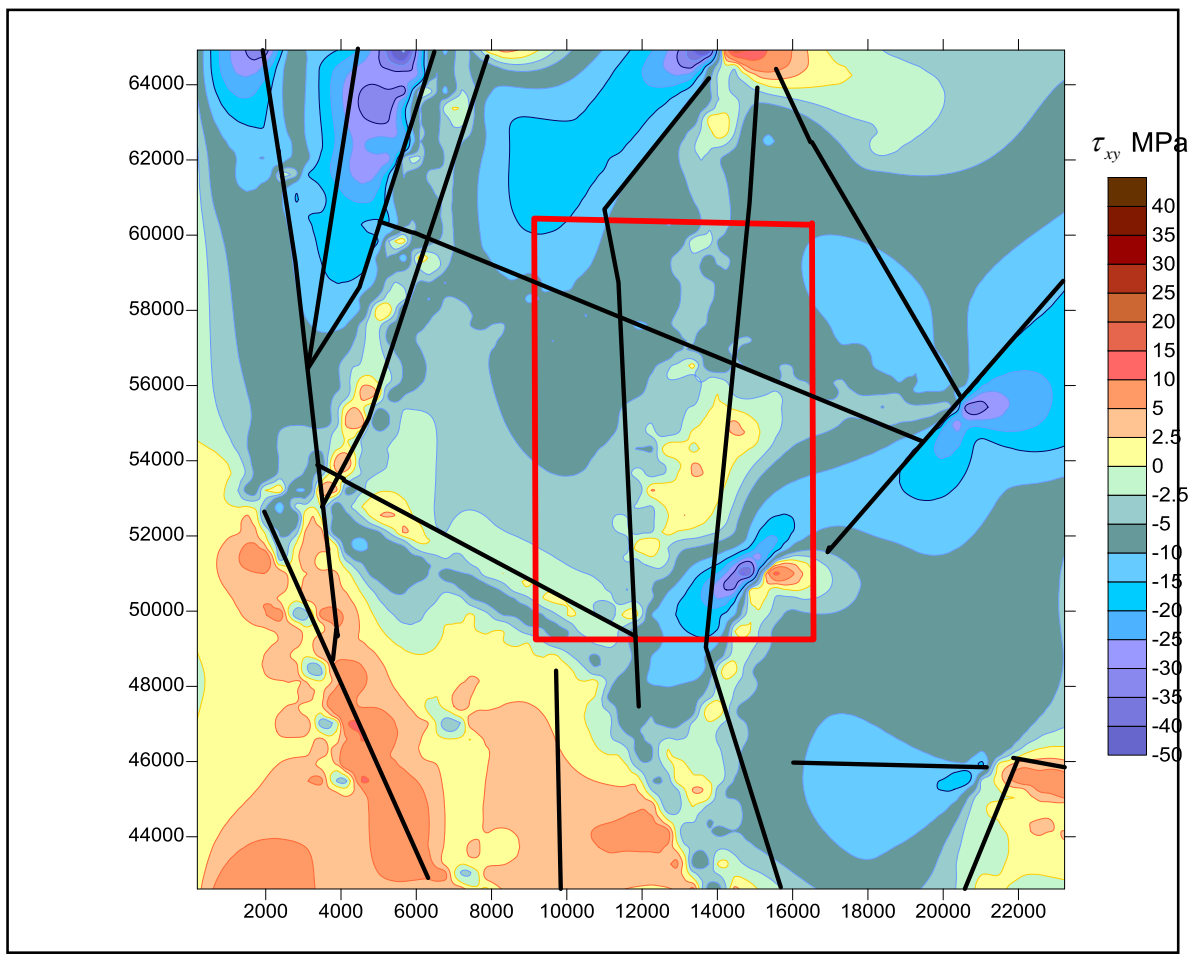

Fig. 6. Distribution of shear stress $\tau_{\mathrm{xy}}$ in «Eniseiskiy»

On this basis, we have identified the two most probable directions of development of new active geodynamic zones affecting of «Eniseiskiy» area. They are displayed in Fig. 7 by 
dotted black lines. These are new the most probable faults in the area of «Eniseiskiy». They should be considered when assessing the environmental safety of HLRW repository.

Fig. 7 displays the distribution of the stress intensity $\sigma_{i}$ and new vectors of filtration rates in the area of «Eniseiskiy» site.

Directions of the vectors correspond to the movement of groundwater in the weakened zone. Vectors of gradients working stresses are directed into the zones of tectonic disturbances (fig 7). Thus, these zones are reservoirs for groundwater flow. Filtration water can also be caused by activation of faults, i.e. run "trigger mechanism" tectonic activity. The faults are the channels of the intensive filtering groundwater, contributing to extensive migration of radionuclide in the geological environment, with the change of tectonic stresses.

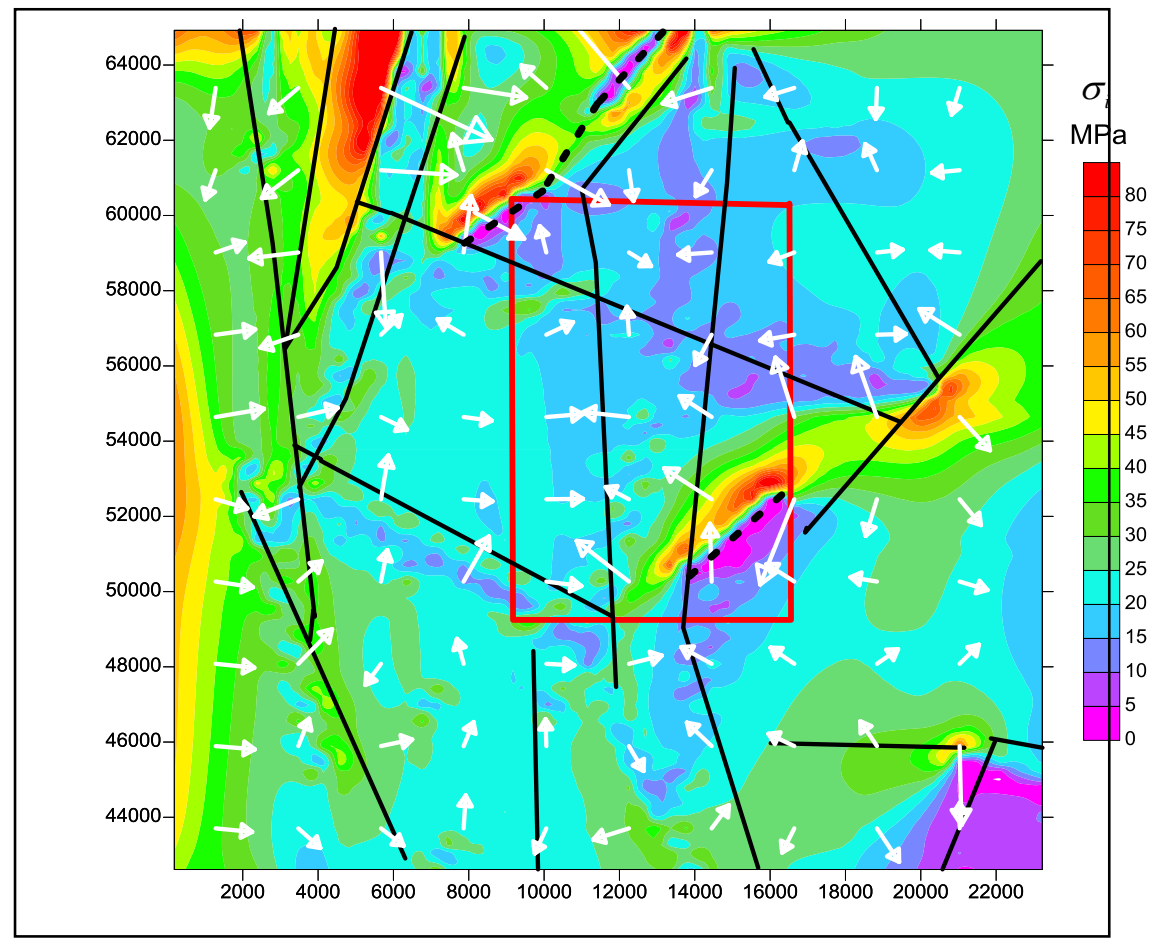

\section{Fig. 7. The distribution of stress intensity in the area «Eniseiskiy» and vectors of filtration rate}

\section{Summary}

Summarizing the foregoing, we can give the following conclusions and recommendations to improve methods of prediction of degradation of the geological environment in relation to the task of choosing the least dangerous area for disposal of high level radioactive waste:

1. Zones of high concentration of stress intensity $\sigma \mathrm{i}$ are the zones of an unstable state of the geological environment within which are more likely to develop of the tectonic destruction of the structural-tectonic blocks with subsequent destruction of the artificial and natural isolation barriers.

2. It is necessary to consider the major relationship between the laws of tectonic stress and the potential threat of mass transfer of radionuclide in the process of groundwater filtration, when choosing the area of placing HLRW cemeteries.

3. Kinematical principles of tectonic destruction of the geological environment in combination with the obtained values of stress intensity and shear stress $\tau_{x y}$ provide an opportunity to build a predictive scheme to destroy the structural blocks as successive iterations of the promotion of active faults with the redistribution of stress field and the 
changing of SDS of rock masses, accompanied by changes in the hydrogeological conditions of the chosen area.

4. Correction of this model is possible, based on the observations of contemporary activity of the major tectonic faults within the area of a radius of $30 \mathrm{~km}$ using the methods of space geodesy.

\section{References}

1. Morozov V.N., Tatarinov V.N. Tectonic processes development with time in the areas of HLRW disposal from expert assessment to prognosis. // Int. Nuclear Energy science and Technology, Vol. 2. No, 1/2. 2006. Pp. 65-74.

2. Morozov V.N., Tatarinov V.N. Methods of selecting areas of the earth's crust to accommodate the environmentally hazardous waste. // Geoecology. M. 1996, № 6, p. 109-120.

3. Belov S.V., Morozov V.N., Tatarinov V.N., Kamnev E.N., Hammer I. Study of the structure and geodynamic evolution of Niznekansky granitoid massif in connection with the disposal of high level radioactive waste // Geoecology. M. 2007, № 3. p. 227-238.

4. Morozov V.N., Gupalo T.A., Tatarinov V.N. Forecast insulating properties of the rock mass in the placement of radioactive materials in mines // Mountain Gazette. 1999, № 6. p. 99-105.

5. Morozov V.N., Kolesnikov I., Belov S.V., Tatarinov V.N., Stress-deformed state of Niznekansky granitoid massif - as the area of possible disposal of radioactive waste. // Geoecology. M. 2008, № 3, p 232-243. 